\title{
A Model for the Estimation of Brake Interface Temperature
}

\author{
Aleksandar Grkić1 ${ }^{*}-$ Davorin Mikluc ${ }^{1}$ - Slavko Muždeka ${ }^{1}$ - Živan Arsenić2 - Čedomir Duboka $^{3}$ \\ 1 University of Defence, Military Academy, Serbia \\ 2 University of Belgrade, Faculty of Mechanical Engineering, Serbia \\ 3 University of Belgrade, Serbia
}

\begin{abstract}
The temperature achieved at the contact surface of the disc and the pad of a friction brake during its operation has a significant impact on brake performance. Temperature measurement techniques, which are usually available under laboratory test conditions, enable obtaining relatively accurate values of the temperature at the friction surface. However, measuring the sliding surface temperature during the entire lifetime of the brake pad is very difficult due to the demanding operating conditions of the brakes, i.e. the appearance of wear, the presence of water, corrosion, and other immersive impacts. Purely mathematical models for the prediction of friction or contact surface temperature are often complex, and they are affected by a number of limitations. In this paper, an appropriate mathematical model was developed in order to enable estimation of the sliding surface temperature values between the brake disk and brake pads throughout the entire duration of brake application. This is achieved by using the results of the temperature measurement within the brake pad and its processing, by means of an originally developed mathematical model.

Keywords: temperature estimation, braking, friction surface, measurement, modelling

\section{Highlights}

- $\quad$ Available temperature measurement techniques and mathematical models for prediction of contact surface temperature.

- Measuring the temperature of the frictional surface and within the brake pad by using thermo couples.

- The model for estimation of temperature on the contact surface of the disc and the pad.

- Analysis of results and validation of the mathematical model.
\end{abstract}

\section{INTRODUCTION}

The braking process is a complex stochastic tribological process by which the motion energy of vehicles is irrevocably transferred into heat and dissipated into the environment. Generally, the amount of heat is a time-related function, depending on the thermal characteristics of the parts enabling friction contact, as well as their size, shape, activation pressure, and sliding speed [1] and [2] .

The temperature on the friction surfaces of automotive brakes can reach very high values. In this sense, it is an influential factor of the brakes' performance [3] to [7]. According to [8], the temperature distribution on the friction surfaces is generated by combined processes and complex phenomena that directly affect brake performance. High temperatures on the friction surface may cause the decrease in efficiency of braking, so called fading [9]. Moreover, extremely high temperatures can cause convex bending of the brake pads and an uneven distribution of pressure leading to uneven wear rate distribution [10].

In [11], it was shown that brake factor values differ significantly depending on the variation of brake interface temperature, which is quite uniform under the same initial brake temperature. This means that, depending on the initial brake temperature, deceleration and braking time significantly differ from one braking application to another. Taking into consideration that the initial brake rotational speed and control line pressure take predetermined and wellknown values, knowing the temperature values of the contact surface enables estimating the coefficient of friction in automotive brakes [12].

Having knowledge of the main influencing values at the initiation of the braking process, and also during braking process, enables the prediction of the output brake parameters, i.e. brake performance can be predicted and thus managed. However, in order to ensure a reliable and efficient management of the braking process, it is necessary to continuously obtain information concerning the actual values of the braking influential parameters. Consequently, it is vital to have knowledge about the temperature on the contact surface of the disk and the brake pads throughout the braking application duration.

It is very difficult to measure and predict the values and character of temperature changes in the brake. Temperature measurements on the contact surface are practically impossible over a longer period, due to the physics of the friction process. Apart from that, automotive brakes work in difficult operating conditions, which is reflected in the appearance of wear, the presence of water, corrosion and so on. Through this task, it is possible to apply several 
different temperature non-contact measurement methods [13], such as optical and infrared methods, and contact type methods, as well as temperature measurement using thermo-couples or different temperature-sensitive materials. According to [14], the most effective way to determine the temperature on the contact surface of the disc and brake pads in the vehicle during braking is by applying thermocouples.

In contrast, a number of authors used different mathematical methods to describe and present temperatures in the contact zone of the friction pair and the behaviour of the temperature field in the braking process, as well as their impact on wear and brake performance. The prediction of brake temperature in the contact surface can be realized in two ways: analytically and numerically [15] to [19]. The basis of the analytical method relies on the Fourier equation of temperature field [20], while the finite element method (FEM) [2] represents the most important numerical method. In recent years, the application of artificial intelligence (AI) methods (such as neural networks) has become a particularly interesting as a tool for predicting temperatures in automotive brakes [21].

All of the above-mentioned methods can provide satisfactory results in comparison the actual measurements. However, the application of any of these methods typically requires numerous simplifications and restrictions in order to offer solutions to the observed problem.

Taking this into consideration, this paper investigates the possibilities of estimating both the character in changes and the values in the contact surface temperature between the disc and brake pads. The developed model is based on the results of temperature measurements in the vicinity of the contact surface and in the depth of a brake pad. A model for estimating the temperature on the contact surface requires continuous information about the temperature values within brake pads by means of measurement. This is possible during the entire working life of brake pads.

\section{EXPERIMENTAL RESEARCH}

As previously stated, temperature measurement in the friction surfaces of a brake is a difficult task. This is due to numerous influencing factors specific to rubbing surfaces such as those in friction brakes, especially since it is necessary to provide temperature measurement with an appropriate accuracy and minimum delay.

When comparing all the available techniques of temperature measurement, the method using thermocouples shows significant advantages over others; they are very effective for measuring the temperature in the contact of the friction pair. In this case, a so-called "hot end" or hot junction is located very close to the friction surface.

However, it must be taken into consideration that the thermocouple should not at any time be exposed to direct rubbing over the friction surface in order to eliminate the potential impact on the quality of the measuring signal of the thermocouple sliding itself over the metal surface as much as possible.

This kind of problems may be avoided if the thermocouple is positioned within the pad, very close to the sliding surface, e.g. $0.5 \mathrm{~mm}$ deep from it (SAE J843). In the present study, one temperature sensor was located in such a position, and it will be used to measure the temperature on the friction surface $\left(T_{1}\right)$. However, given the requirement that the temperature at the friction surface be measured throughout the lifespan of brake pads, this position is not satisfactory due to wearing phenomena.

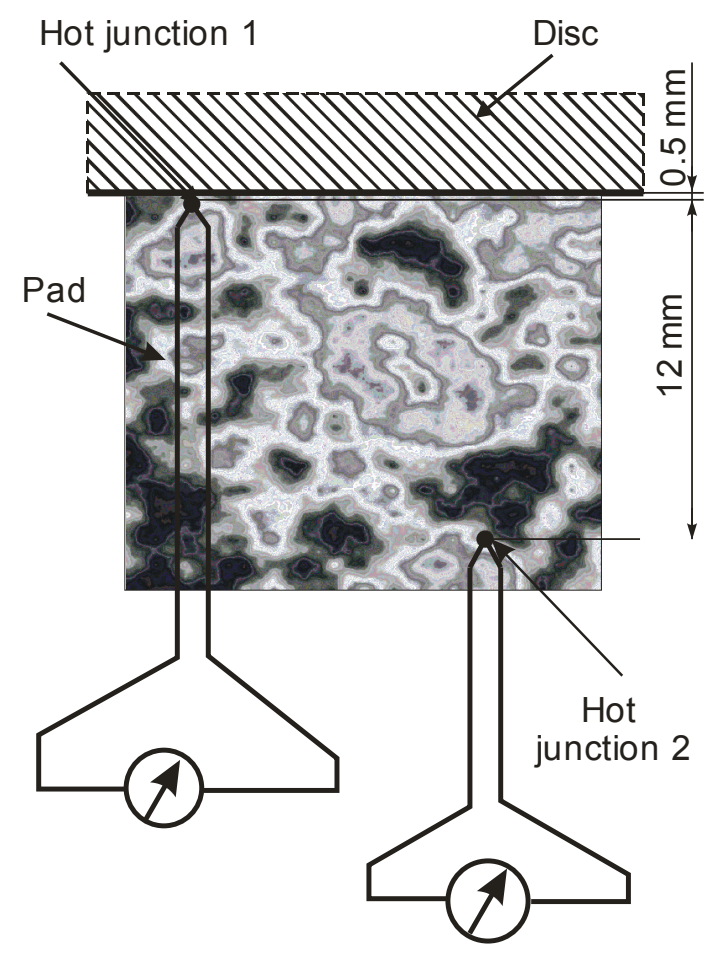

Fig. 1. Position of thermocouples in brake pad

Therefore, another thermocouple $T_{2}$ will be positioned $12.5 \mathrm{~mm}$ deep from the contact surface, within the pad, as shown in Fig.1. The position of this thermocouple is close to the backing plate, and it is defined by the thickness of the brake lining material. This thermocouple is not exposed to the effects 
of wearing, which ensures its use throughout the operating period.

It is important to note that both thermocouples were placed at the friction radius of the pad.

Typical test results of the temperature measurement are presented in Fig. 2; the solid line shows temperature measurement results at the sliding surface (i.e. $0.5 \mathrm{~mm}$ deep from the friction surface), while the dahed dot line shows temperature measurement results $12.5 \mathrm{~mm}$ deep from the friction surface of the disc pad. The measurement was carried out at the Frimeks laboratory of the Faculty of Mechanical Engineering, University of Belgrade, with a car disc brake tested at a single-ended full-scale inertia dynamometer [11].

Temperature measurements were carried out during 5 consecutive (or repeated) full-stop brake applications over a total time of 600 seconds, with an initial brake speed corresponding to linear vehicle speed of $60 \mathrm{~km} / \mathrm{h}$, and with the control line pressure of $60 \mathrm{bar}$, while the initial brake temperature at the beginning of the measurement cycle was $100{ }^{\circ} \mathrm{C}$ $\left( \pm 3^{\circ} \mathrm{C}\right)$. The brake was subject to cooling by means of the fan operating throughout the measurement period.

In each brake application, a brake disc was first accelerated until it reached the predetermined initial brake speed, and consequently braked to a full stop. After completing a single brake application, the brake disc remained at a standstill. Speeding up of the disc for the next brake application started a few moments before the brake attained a predetermined initial temperature of $100^{\circ} \mathrm{C}$.

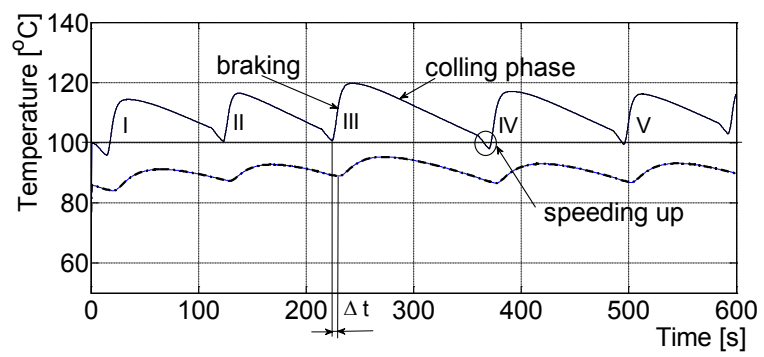

Fig. 2. Temperatures measured in the disc pad for 5 consecutive brake applications

This can also be seen in Fig. 2, where the change in the shape of the curve representing temperature measurement is evident in the area near the end of the cooling phase. This occurs because the brake temperature decreases significantly faster due to rotating disc during the speed build-up period. The delay in reaching the minimum temperature value at the depth of $12.5 \mathrm{~mm}$ from the sliding surface when compared to the minimum temperature "at the friction surface" is represented with the symbol $\Delta t$, as shown in Fig. 2.

\section{TEMPERATURE MODELLING ON THE FRICTION SURFACE}

The model for estimation of temperature on the contact surface of the disc and the pad is based on the temperature ratio $(k)$, which is determined experimentally as a rate between temperatures $T_{1}$ and $T_{2}$ at hot junctions 1 and 2, respectively, as shown in Fig. 1 above, by means of the test results from Fig. 2 .

The evaluation of $k$ factor (temperature ratio) between temperatures $T_{1}$ and $T_{2}$ is shown in Fig.3.

As shown in Fig. 3, the values of $k$ factor vary between $k_{\min }=1.14$ and $k_{\max }=1.32$. It may be seen from both Figs. 2 and 3 that $k$ factor certainly depends and varies on whether the brake was in the warming (brake application) or cooling (brake release) phase.

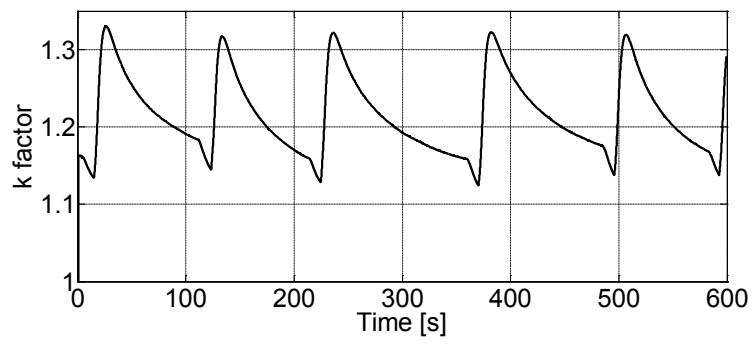

Fig. 3. $k$-factor between temperatures $T_{1}$ and $T_{2}$

Therefore, the $k$ factor may be best represented by its mean value, which can be determined as follows:

$$
k=\frac{k_{\min }+k_{\max }}{2} .
$$

The estimated value of the temperature $T_{E}$, which represents the modelled values of the friction sliding surface temperature $T_{1}$ can be obtained by multiplying the temperature value $T_{2}$, which was measured in the depth of a pad with the mean value of the $k$ factor.

Variations of $k$ factor also depend on the composition of the brake pad friction material, wear status, brake geometry and operating conditions, as well as the position of thermocouple $T_{2}$ in the depth of friction material.

It is important to emphasize that this model for prediction of temperature on the friction surface is limited to the brake under examination only, in addition to the given friction material characteristics and the position defined for $T_{2}$ temperature measurement. 
The temperature $T_{1}$ was not used in the model; it only represents control parameter in order to assess the quality of the model.

Fig. 4 shows the results already presented in Fig. 2 in order to enable first approximation in resolving this situation with the help of a new dashed line for $T_{\mathrm{E}}$. This represents the results of continuous multiplication of the "pad inside temperature" $T_{2}$ values (dashed dot line) by the mean value of the $k$ factor, thus obtaining a "predicted" value of the temperature $T_{E}$, which will correspond to the correct value of the temperature $T_{1}$ (solid line) in the contact surface, as measured during the test.

However, it is obvious that such an estimation of brake-sliding surface temperature is not only applicable to the given brake characteristics, including those related to the friction material used, but also to the given combination of the initial braking conditions (speed and pressure). The big question, in this case, would not be how to calculate the values of the sliding surface temperature accurately, but how to reach a universal relationship between the brake contact surface temperature and the temperature within the pad, i.e. at a given depth from the sliding surface.

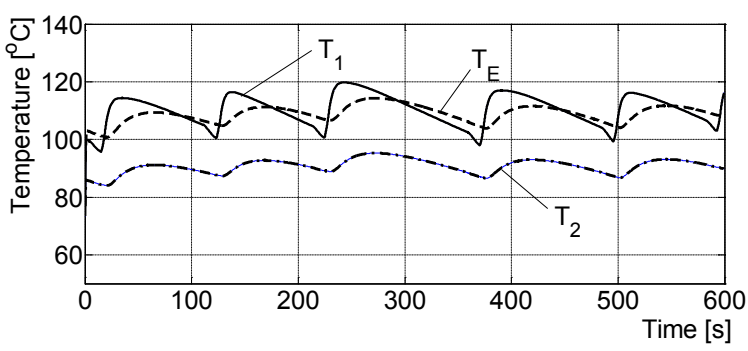

Fig.4. Result of the correction of temperature $T_{2}$ (dashed dot line) by means of the $k$-factor for temperature $T_{E}$ (dashed line) compared to temperature $T_{1}$ (solid line)

It is evident that the estimated temperature $T_{E}$ does not fully correlate with the temperature $T_{1}$ on the contact surface, neither by value nor by shape, because it follows the shape of the temperature $T_{2}$. It is also apparent that the temperature $T_{2}$ demonstrates a certain delay in the gain, not only during the application or braking process, but also during free running in the cooling process. This is caused by the heat transfer through the friction material.

It is well known that the heat transfer through the friction pad is a highly complex issue, but the idea of this paper was not to study it in a more detailed form. The results of the measurement and calculation using the $k$ factor shows that in addition to the proportionality between the measured and estimated temperature as defined by $k$ factor, there must also be a certain influence of the time, speed, and the deceleration of the heat transfer through the friction pad, starting from the sliding surface and ending somewhere in the depth of it, where the temperature $T_{2}$ can be measured.

Bearing all this in mind, the model for the brake contact surface temperature estimation was developed in the following general form based on polynomial regression [22]:

$$
T_{E}(t)=T_{2}(t) \cdot k+\frac{d T_{2}}{d t} \cdot t \cdot k_{v}+\frac{d^{2} T_{2}}{d t^{2}} \cdot \frac{t^{2}}{2} \cdot k_{a},
$$

where $T_{E}$ is the estimated brake interface temperature, $T_{2}$ the temperature measured within the pad, $t$ the time, $k$ the temperature ratio, and $k_{v}$, and $k_{a}$ are coefficients representing speed and acceleration of temperature increase intensity, i.e. representing the coefficients of heat transfer through the friction material.

These coefficients also depend on the composition of the brake pad friction material, wear status, brake geometry and operating conditions, as well as the position of thermocouple $T_{2}$ in the depth of the friction material.

The coefficient of the speed of temperature increase intensity $k_{v}$ is determined by fitting the estimated temperature $T_{E}$ to the measured temperature $T_{1}$. This process is performed in the sequence of monotonous temperature change in order to avoid the influence of coefficient $k_{a}$ from Eq. (2).

Because the estimated temperature $T_{E}$ change does not fully correlate to that of the temperature $T_{1}$, neither by value nor by shape, the value of the coefficient $k_{v}$ was calculated with a simple linear regression method based on the least squares criterion [22] and [23] using measurement data of $T_{1}$ and $T_{2}$ temperatures. Now, the coefficient $k_{a}$ remains the only unknown parameter in Eq. (2). The least squares criterion will give best value for parameter $k_{a}$ for the process model using the polynomial regression method [22] and [23] between the measured temperatures $T_{1}$ and $T_{2}$. After this procedure, the estimated temperature $T_{E}$ could be calculated.

The thus obtained estimated (i.e. calculated) brake contact surface temperature $T_{E}$ is presented by means of the dashed line in Fig. 5, where it can be seen that estimated temperature $T_{E}$ follows both the shape and the character of the behaviour of measured temperature $T_{1}$ very well, which seems to deviate from the actual value by not more than $\pm 3{ }^{\circ} \mathrm{C}$.

This deviation can be assumed to come from the noise of the measurement signal, being the result of 
conditions by which measurement was carried out, and a high sampling rate selected, even though it is a relatively slow process.

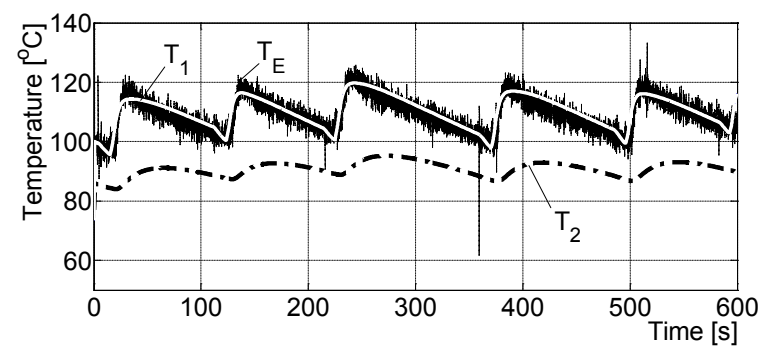

Fig. 5. Estimated temperature $T_{E}$ in the contact surface

Apart from this, if we further note that the calculated temperature was obtained by including the first and the second derivative of temperature changes, then it becomes clear why the noise signal was so strong. The resulting signal is cleaned by applying a filter with constant coefficients; the proposed filter is the alpha-beta-gamma filter. Determination of $\alpha, \beta$, and $\gamma$ coefficients yields the following results according to [24]:

$$
\begin{gathered}
\alpha=0.95, \\
\beta=2 \cdot(2-\alpha)-4 \cdot \sqrt{(1-\alpha)}, \\
\gamma=\frac{\beta^{2}}{2 \cdot \alpha} .
\end{gathered}
$$

Within the first step of determination, the signal of measured temperatures inside the brake pads was filtered, after which the estimation of temperature on the contact surface according to Eq. (1) was made. The result is a signal, i.e. the temperature at the contact surface (in black) as shown in Fig. 6; the figure shows that the filtered signal follows the actual (real) value of the measured temperature on the contact surface, with the average deviation of $\pm 1^{\circ} \mathrm{C}$, but there is also some delay when compared to the measured value.

The reason for this may be the choice of filters with constant coefficients, while the values of these thermal conductivity coefficients in friction material depend on the temperature changes on the contact surface.

Fig. 7 shows the delay in the estimated temperature value in relation to the measured temperature, which begins to increase at the same time as the temperature measured inside the disc pad.

The time of delay is proportional to the thickness of the friction material and the value of the difference between the temperature on the friction surface and inside the pads, respectively.

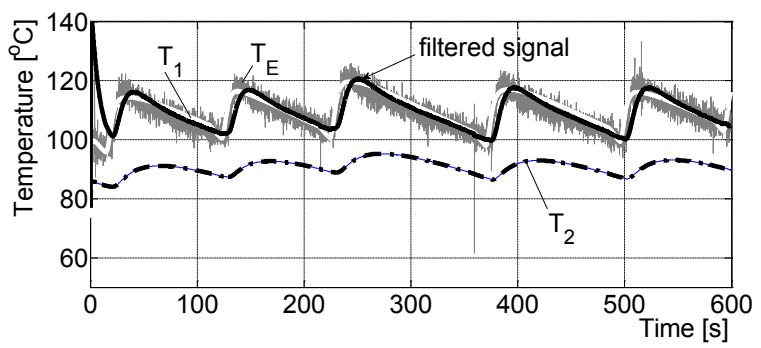

Fig. 6. Results of signal filtering using $\alpha-\beta-\gamma$ filters

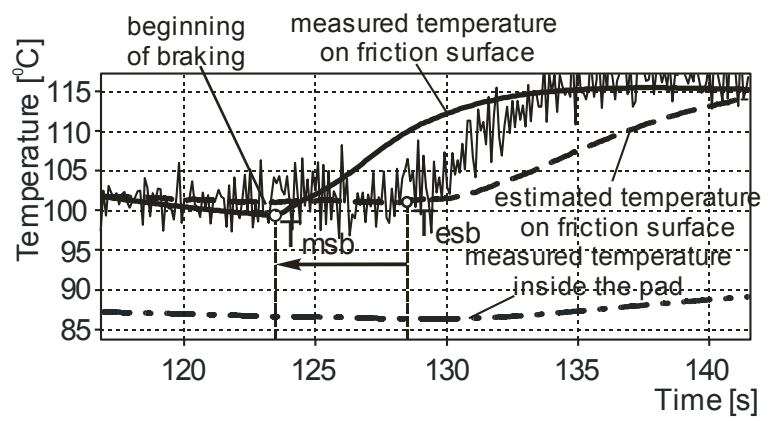

Fig. 7. Delay in the estimated temperature value in relation to the measured temperature
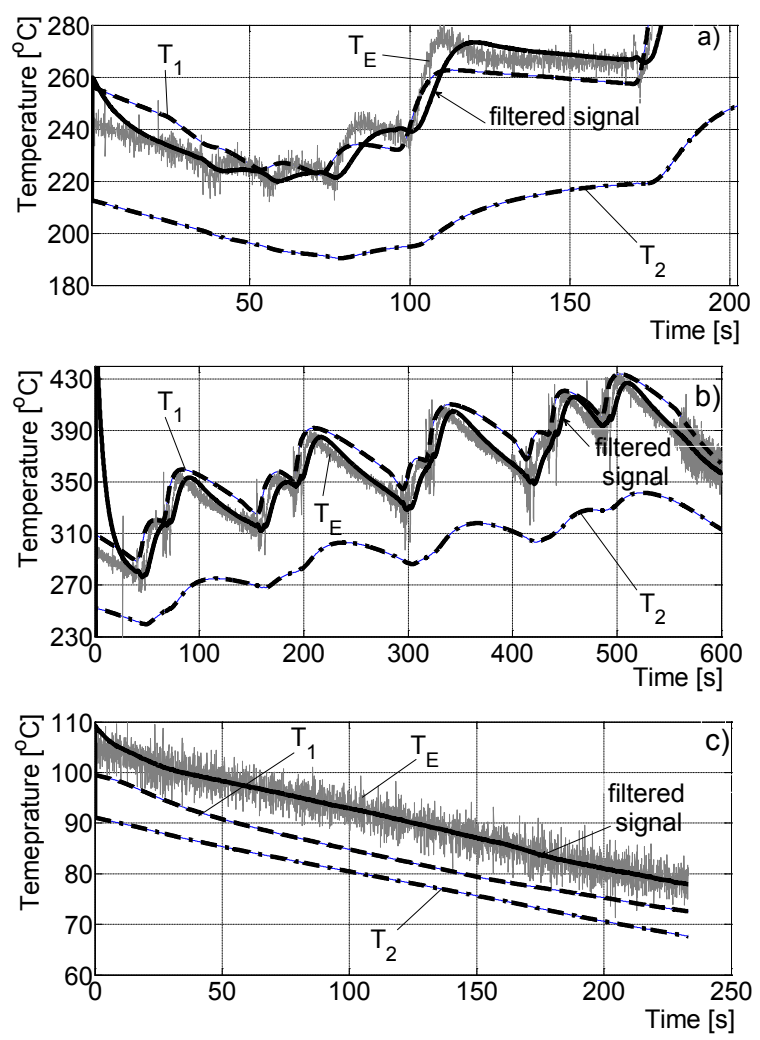

Fig. 8. Estimation of temperature on the friction surface under different brake operating conditions 
Fig. 8 shows the results of the research on the estimation of the friction surface temperature during different brake-operating conditions.

Fig. 8a shows an estimated friction surface temperature under operating conditions of high braking temperatures, while Fig. $8 \mathrm{~b}$ displays the results under operating conditions with extremely high temperatures.

In both cases, measurements were carried out during consecutive full-stop brake applications with an initial brake speed and control line pressure, different in relation to the test on the basis of which a mathematical model was introduced.

Fig. 8c shows the results of the evaluation of temperature in the cooling phase. The assessment was conducted using a previously described model without any change in the values of the coefficients $\left(k, k_{v}, k_{a}\right.$, $\alpha, \beta$ and $\gamma$ ).

\section{CONCLUSION}

This paper presents the results of the estimation of the sliding surface temperature of a brake during the whole braking application. The estimated value of the contact surface temperature was obtained by means of the presented mathematical model, including the results of temperature measured inside the brake pad at a given depth.

Previous research shows that the estimated temperature on the contact surface follows the nature of the change in actual temperature very well, as well as the measured temperature on the contact surface with the average deviation around the actual value of $\pm 1^{\circ} \mathrm{C}$.

The presented model of estimation of temperature on the friction surface is limited to the brake under examination, in addition to the given friction material and the position defined by the second thermocouple, placed in the depth of the disc pad and the given operating conditions. Here, it was also shown that by using the presented model, the temperature on the friction surface can be assessed even in the case of different operating conditions (sliding velocity, pressure, and temperature), but with significant deviations.

The presented results reveal an evident delay of the assessed temperature flow compared to the temperature measured on the contact surface. The cause for this is heat transfer through the friction surface. In other words, based on the temperature inside the pads, one can fairly and accurately estimate the temperature on the friction surface during braking, but cannot be informed about the initial moment of braking.

Future research will relate to the creation of models with varying coefficients $k, k_{v}, k_{a}$, as a function of the operating conditions of the brake for other types of friction materials.

\section{REFERENCES}

[1] Ostermeyer, G.P., Graf, M. (2013). Influence of wear on thermoelastic instabilities in automotive brakes. Wear, vol. 308, no. 1-2, p. 113-120, D0l:10.1016/j.wear.2013.09.009.

[2] Day, A.J., Newcomb, T.P. (1984). Dissipation of frictional energy from the interface of an annular disc brake, Proceedings of the Institution of Mechanical Engineers, Part D: Journal of Automobile Engineering, vol. 198, no. 11, p. 201-209, DOI:10.1243/PIME_PROC_1984_198_146_02.

[3] Emery, A.F., Kumar, P., Firey, J.C. (1997). Experimental Study of Automotive Brake Systems Temperatures. Washington State Transportation Center (TRAC), University of Washington, Washington.

[4] Talati, F., Jalalifar, S. (2008). Investiga-tion of heat transfer phenomena in a ventilated disk brake rotor with straight radial rounded vanes. Journal of Applied Sciences, vol. 8, no.20, p.3583-3592, DOI:10.3923/jas.2008.3583.3592.

[5] Litos, P., Honner, M., Lang, V., Bartik, J., Hynek, M. (2008). A measuring system for experimental research on the thermo mechanical coupling of disc brakes, Proceedings of the Institution of Mechanical Engineers, Part D: Journal of Automobile Engineering, vol. 222, no. 7, p. 1247-1257, DOI:10.1243/09544070JAUT0593.

[6] Bansal, D.G., Streator, L.J. (2009). A method for obtaining the temperature distribution at the interface of sliding bodies. Wear, vol. 266, no. 7-8, p. 721-732, D0l:10.1016/j. wear.2008.08.019.

[7] Cho, H.-J., Cho, C.-D. (2008). A study of thermal and mechanical behaviour for the optimal design of automotive disc brakes. Proceedings of the Institution of Mechanical Engineers, Part D: Journal of Automobile Engineering, vol. 222, no. 6, p. 895-915, D0I:10.1243/09544070JAUT0722.

[8] Talati, F., Jalalifar, S. (2009). Analysis of heat conduction in a disk brake system. Heat Mass Transfer, vol. 45, no. 8, p. 10471059, DOl:10.1007/s00231-009-0476-y.

[9] Duboka, Č., Arsenić,Ž., Milosavljević, M. (1996). Tribomutations in tribo-mechanical systems. $2^{\text {nd }}$ International Conference on Tribology, Thessalonniki.

[10] Eriksson, M., Bergman, F., Jacobson, S. (2002). On the nature of tribological contact in automotive brakes. Wear, vol. 252, no. 1-2, p. 26-36, D0l:10.1007/s00231-009-0476-y.

[11] Grkić, A., Mikluc, D., Perić, S., Duboka, Č. (2013). Prediction of disc brake contact surface temperatures. 24. International Automotive Conference Science and Motor Vehicle, Belgrade.

[12] Grkic, A., Muzdeka, S., Arsenic, Z., Duboka, C. (2014). Model for estimation of the friction coefficient in automotive brakes under extremely high temperatures. International Journal of Engineering and Technical Research, vol. 2, no. 11, p. 290294. 
[13] Dinc, O.S.C., Ettles, M., Calabrese, S.J., Scarton, H.A. (1993). The measurement of surface temperature in dry or lubricated sliding. Transaction of ASME, Journal of Tribology, vol. 115, no. 2, p. 78-82, DOI:10.1115/1.2920989.

[14] Qi, H.S., Day, A.J. (2007).Investigation of disc/pad interface temperatures in friction braking. Wear, vol. 262, no. 5-6, p. 505-513, D0I:10.1016/j.wear.2006.08.027.

[15] Golubev, Yu. A., Ivanenko, V.V. (2009). A calculation method of energy intensity of brake lining wear as related to temperature. Journal of Friction and Wear, vol. 30, no. 4, p. 258-260, DOI:10.3103/S1068366609040059.

[16] Evtushenko, A.A., Ivanik, E.G. (1999).Evaluation of the contact temperature and wear of a composite friction pad in braking. Journal of Engineering Physics and Thermophysics, vol. 72, no. 5, p. 955-962, Dol:10.1007/BF02699422.

[17] Matysiak, S., Evtushenko, 0., Kuciej, M. (2007).Temperature field in the process of braking of a massive body with composite coating. Materials Science, vol. 43, no. 1, p. 62-69, DOI:10.1007/s11003-007-0006-3.

[18] Yevtushenko, A.A., Kuciej, M. (2011). The thermal problem of friction for a three-element tribosystem with composite strip. International Journal of Heat and Mass
Transfer, vol. 54, no. 25-26, p. 5427-5437, D0l:10.1016/j. ijheatmasstransfer.2011.07.048.

[19] Chichinadze, A.V. (2009). Theoretical and practical problems of thermal dynamics and simulation of the friction and wear of tribocouples. Journal of Friction and Wear, vol. 30, no. 3, 199215, DOI:10.3103/S106836660903009X.

[20] Tirovic, M., Stevanovic, D., (1986). Determination of temperature Field Disc Brake Pads. MVM, Kragujevac.

[21] Ray, S., Chowdhury, S.K.R. (2009). Prediction of contact temperature rise between rough sliding bodies: An artificial neural network approach. Wear, vol. 266, no. 9-10, p. 10291038, D0I:10.1016/j.wear.2009.02.016.

[22] Weisberg, S. (2005). Applied Linear Regression, John Wiley \& Sons, Hoboken, D0l:10.1002/0471704091.

[23] Grossman, M. (1971). Parametric curve fitting, The Computer Journal, vol. 14, no. 2, p. 169-172, D0l:10.1093/ comjnl/14.2.169.

[24] Tenne, D., Singh T. (2002). Characterizing performance of $\alpha-\beta-\gamma$ filters. Aerospace and Electronic Systems, IEEE Transactions, vol. 38, no. 3, p. 1072-1087, D0l:10.1109/ TAES.2002.1039425. 